\title{
Posterior Reversible Encephalopathy Syndrome Induced by Pazopanib in a Patient with Soft-Tissue Sarcoma: A Case Report
}

\author{
Chien-Ting Wu, Chieh-Tsung Yen, Hsiu-Lan Cheng, Chi-Hui Lee \\ Department of Pharmacy, Dalin Tzu Chi Hospital, Buddhist Tzu Chi Medical Foundation, Taiwan \\ Email: xelox78123@gmail.com
}

How to cite this paper: $\mathrm{Wu}, \mathrm{C} .-\mathrm{T} .$, Yen, C.-T., Cheng, H.-L. and Lee, C.-H. (2019) Posterior Reversible Encephalopathy Syndrome Induced by Pazopanib in a Patient with Soft-Tissue Sarcoma: A Case Report. Case Reports in Clinical Medicine, $\mathbf{8}$, 127-133.

https://doi.org/10.4236/crcm.2019.85014

Received: April 13, 2019

Accepted: May 20, 2019

Published: May 23, 2019

Copyright $\odot 2019$ by author(s) and Scientific Research Publishing Inc. This work is licensed under the Creative Commons Attribution International License (CC BY 4.0).

http://creativecommons.org/licenses/by/4.0/

(c) (i) Open Access

\begin{abstract}
Posterior reversible encephalopathy syndrome (PRES), a rare disease is characterized by multiple neurological complications. It has been reported to be associated with the use of angiogenesis inhibitors such as sorafenib, sunitinib, pazopanib, regorafenib, and lenvatinib. We reported a case of 76-year-old woman with history of stage III hepatocellular carcinoma (HCC), who developed adverse drug reactions related to pazopanib induced PRES. Pazopanib, an angiogenesis inhibitor which inhibits the vascular endothelial growth factor (VEGF) pathway may lead to vascular endothelial damage, and these pathophysiological changes may lead to vascular leaks and brain edema. Medical staff must be aware of the possible association between angiogenesis inhibitors and the development of PRES. In patients with retroperitoneal soft-tissue sarcoma undergoing treatment with pazopanib, regular monitoring of their blood pressure and following-up brain magnetic resonance imaging (MRI) should be encouraged.
\end{abstract}

\section{Keywords}

Posterior Reversible Encephalopathy Syndrome, Pazopanib, Hepatocellular Carcinoma, Vascular Endothelial Growth Factor, Magnetic Resonance Imaging

\section{Introduction}

Posterior reversible encephalopathy syndrome (PRES) is a rare disease, which is characterized by multiple neurological complications [1] such as seizures and hypertensive emergencies [1] [2]. Commonly clinical manifestations of PRES include severe headache, confusion, seizures and visual disturbances, as 
well as signs of symmetrical white matter edema [3] under brain magnetic resonance imaging (MRI) study [1]. In the last few years an increased number of case reports involving new targeted drugs, particularly angiogenesis inhibitors such as sorafenib, sunitinib, pazopanib [4], regorafenib [5], lenvatinib [6] and other targeted drugs have been implicated in new cases of PRES [3]. This case represented a patient with hepatocellular carcinoma (HCC) under pazopanib using that developed multiple clinical adverse reactions including signal change under MR image study, which elicits highly suspicious of pazopanib induced PRES.

\section{Case Presentation}

We present the case of a 76-year-old woman, who has history of stage III hepatocellular carcinoma (HCC), and ureter tumor s/p left nephrectomy and ureterectomy. She also has underlying medical illness such as diabetes and end stage renal disease under regular hemodialysis three times a week in the San Joseph's Hospital. Her HCC and bladder tumor was under regular medical follow-up in the Chia Yi Christian hospital. The HCC was under medication controlled with pazopanib $400 \mathrm{mg}$ BID PO since Oct. 26, 2017, and combined with oral drugs at home since Oct. 7, 2017 (shown in Table 1). At 7 o'clock on Oct. 29, the patient was found having four limbs generalized myoclonic movement accompanied with upward gazing with the duration persisted for about 5 minutes at home, and she was then brought to our hospital for medical attention. Her consciousness became drowsy after arrival of the paramedical and similar episode attacked again in the ambulance. She never has any previous history of seizure attack neither fever, chills nor headache. At the ER, her vital signs (T/P/R) were 36.6/98/19 and the NBP was $93 / 77 \mathrm{mmHg}$, the neurologic examination demonstrated isocoric pupils with size about $2.5 \mathrm{~mm}$, both reactive to the light, and the muscle power of four limbs were three fractions. Under the impression of myoclonic seizure, $2 \mathrm{mg}$ lorazepam was stat given with intravenous drip, $1000 \mathrm{mg}$ levetiracetam was loading intravenously, and CNS dose ceftriaxone was administrated, and she was admitted into the medical intensive care unit for close monitoring. The MRI obtained on Oct. 30, 2017 revealed multiple high signal change with edematous areas over subcortical region of frontoparietal lobe, periventricular region, occipital lobe, splenium, and hemisphere of cerebellum (Figure 1). Owing to the symptoms associated with acute changes in consciousness and seizures, along with exacerbated systemic hypertension (shown in Table 2), PRES associated with the use of pazopanib was highly suspected, and pazopanib was discontinued on Oct. 11, 2017. Under the impression of PRES with associated clinical symptoms, she was treated with the anti-convulsant (levetiracetam 500 mg TID PO and clonazepam $0.5 \mathrm{mg}$ HS PO) continuously for more than 1 month, and simultaneously anti-hypertensive drugs were administrated (continuously intravenous infusion of nicardipine for two days, followed by intravenous labetalol, and then switch to amlodipine orally) for keeping systolic blood pressure 

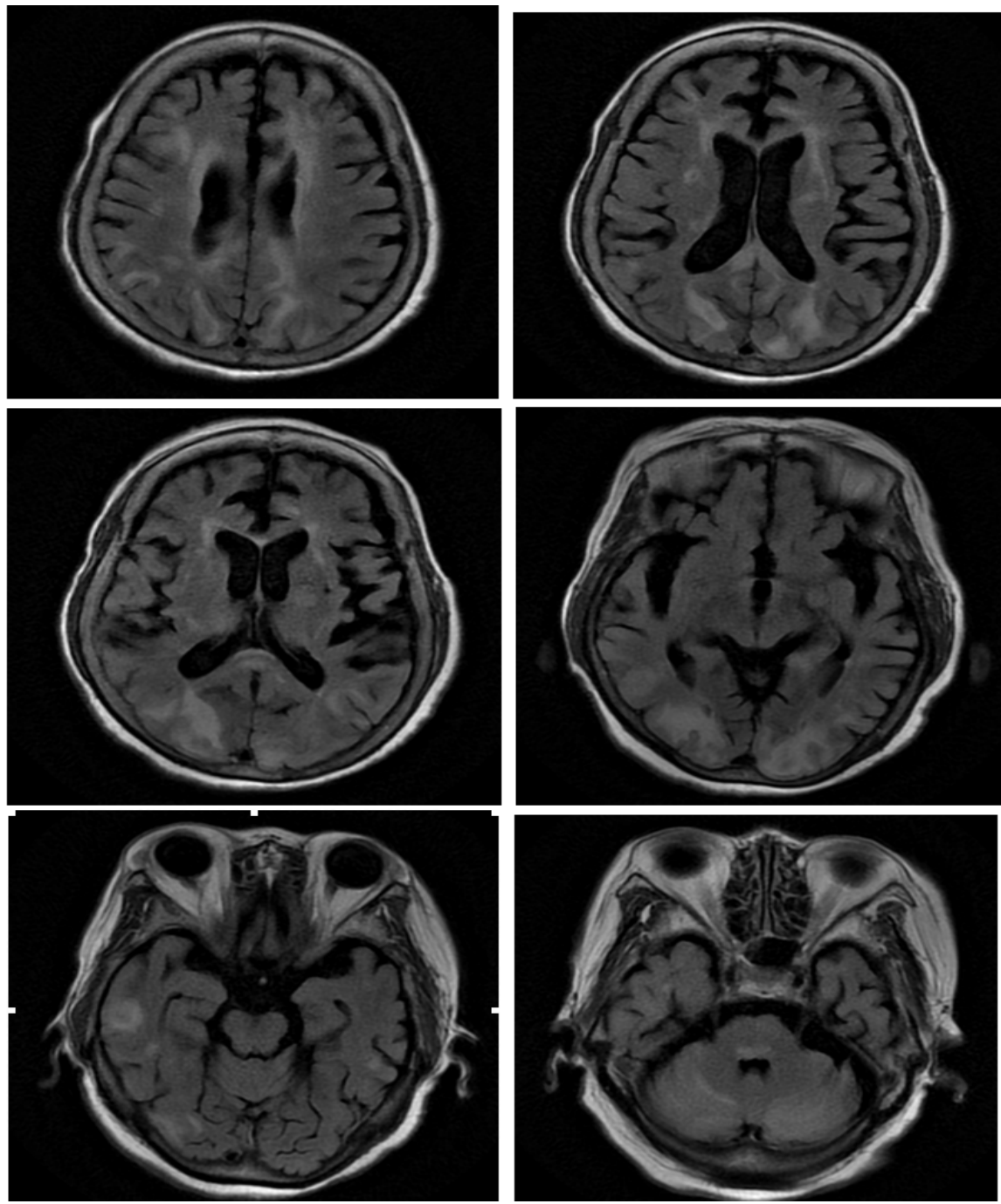

Figure 1. Brain MR images revealed hyper-intense signals over subcortical region of bil. frontoparietal lobe and periventricular area (top 2 figure), splenium (mid. left), and bil. occipital lobes (mid. right), right lateral-temporal lobe (bottom left), and dorsal pons, as well as bil. hemisphere of cerebellum (bottom right) in the patient with PRES.

Table 1. Daily oral drugs before PRES presentation with the patient.

\begin{tabular}{cccc}
\hline Name of Drugs & Dosage & Frequent & Oral Route \\
\hline Pazopanib & $400 \mathrm{mg}$ & BID & PO \\
Thiamine \& Riboflavin & $50 \& 5 \mathrm{mg}$ & QD & PO \\
Folic Acid & $5 \mathrm{mg}$ & QD & PO \\
Famotidine & $20 \mathrm{mg}$ & BID & PO \\
Calcitriol & $0.75 \mathrm{mcg}$ & QW135 & PO \\
Cortisone & $25 \mathrm{mg}$ & QD & PO \\
Clonazepam & $0.25 \mathrm{mg}$ & TID & PO \\
Clonazepam & $0.5 \mathrm{mg}$ & HS & PO
\end{tabular}


Table 2. Daily vital sign in the patient with PRES within the seventh hospital day.

\begin{tabular}{|c|c|c|c|c|c|}
\hline Date & Time & $\begin{array}{c}\text { Temperature } \\
\left({ }^{\circ} \mathrm{C}\right)\end{array}$ & $\begin{array}{l}\text { Pulse Rate } \\
\text { (min) }\end{array}$ & $\begin{array}{l}\text { Respiratory Rate } \\
\text { (min) }\end{array}$ & $\begin{array}{l}\text { Blood Pressure } \\
(\mathrm{mmHg})\end{array}$ \\
\hline \multirow[t]{3}{*}{$10 / 29$} & 1100 & 36.5 & 98 & 21 & $175 / 89$ \\
\hline & 1600 & 36.5 & 100 & 22 & $191 / 100$ \\
\hline & 2100 & 37.2 & 92 & 20 & $189 / 96$ \\
\hline \multirow[t]{3}{*}{$10 / 30$} & 900 & 36.5 & 80 & 20 & $166 / 85$ \\
\hline & 1300 & 36.6 & 66 & 16 & $168 / 85$ \\
\hline & 2100 & 35.7 & 79 & 18 & $109 / 61$ \\
\hline \multirow[t]{3}{*}{$10 / 31$} & 900 & 36.5 & 90 & 16 & $150 / 67$ \\
\hline & 1300 & 36.3 & 96 & 16 & $131 / 68$ \\
\hline & 2100 & 36.6 & 76 & 16 & $135 / 69$ \\
\hline \multirow[t]{3}{*}{$11 / 1$} & 900 & 37 & 88 & 15 & $160 / 71$ \\
\hline & 1300 & 37 & 78 & 15 & $120 / 58$ \\
\hline & 2100 & 36 & 80 & 18 & $147 / 69$ \\
\hline \multirow[t]{3}{*}{$11 / 2$} & 900 & 36.7 & 81 & 20 & $116 / 67$ \\
\hline & 1300 & 36.4 & 79 & 18 & $121 / 65$ \\
\hline & 2100 & 36.8 & 83 & 19 & $145 / 76$ \\
\hline \multirow[t]{3}{*}{$11 / 3$} & 900 & 36.5 & 72 & 18 & $109 / 60$ \\
\hline & 1300 & 36.2 & 65 & 18 & $104 / 50$ \\
\hline & 2100 & 36.7 & 76 & 21 & $131 / 57$ \\
\hline \multirow[t]{3}{*}{$11 / 4$} & 900 & 37.1 & 77 & 18 & $109 / 64$ \\
\hline & 1300 & 37.2 & 73 & 22 & $113 / 56$ \\
\hline & 2100 & 36.6 & 78 & 20 & $138 / 66$ \\
\hline
\end{tabular}

around 100 to $130 \mathrm{mmHg}$. Her symptoms were gradually improved on the fifth hospital day. Due to advanced blood pressure control, she completely regained consciousness with gradually symptom improved on the fifth hospital day, and there was no subsequently new onset neurologic deficits nor clinical seizure attack on the following days, and she was discharged on Oct. 27, 2017. The anti-epileptic drugs such as levetiracetam and clonazepam were continued for symptoms control after discharge.

\section{Discussion}

After reviewing medication profile and further analyzing with reference of relevant literatures, we suspected PRES associated with the use of pazopanib. PRES, which can be fatal, was reported in patients who received pazopanib. Pazopanib should be permanently discontinued if patients associated with the development of PRES [7]. Pazopanib is an oral tyrosine kinase inhibitor (TKIs) that blocking vascular endothelial growth factor (VEGF), platelet-derived growth factor receptor and c-Kit signaling to inhibit the proliferation of tumor cells, and is ap- 
proved for use in advanced renal cell carcinoma and soft-tissue sarcoma, currently [2] [8]. Pazopanib significantly improved the progression-free survival (PFS) of patients with soft tissue sarcoma, but $41 \%$ of patients will cause hypertension, acute and severe hypertension may cause vasodilation and imbalance of brain auto regulation (disruption of cerebral autoregulation), which causes a breakdown of the blood-brain barrier [1]. In Neurologic effects, $10 \%$ of patients cause headaches, confusion, seizures, and visual impairment. Inhibition of the VEGF pathway may lead to vascular endothelial damage, and these pathophysiological changes may lead to vascular leaks and brain edema, which seriously causes PRES [1]. The hallmark of PRES in the majority of the cases of clinical symptoms and brain imaging findings, usually occurs within days to weeks. The major adverse events include: malignant hypertension, preeclampsia, eclampsia and some post-transplant drug treatments (tacrolimus and cyclosporine) or autoimmune disease [3]. In a typical case, angiogenic edema in the apical and posterior frontal lobes is usually seen on the neuroimaging [1] [3]. On vascular images, there are often diffuse vasoconstriction, irregular or partial vasoconstriction of blood vessels, and vasodilation [2] [9]. In a randomized, double-blinded, controlled study of soft tissue sarcoma treatment, the results found that approximately $42 \%$ of patients with soft tissue sarcoma who received pazopanib associated with the development of hypertension (systolic blood pressure $>150$ or diastolic blood pressure $\geq 100 \mathrm{mmHg}$ ) and hypertensive crisis. Hypertension occurs early in the course of treatment ( $40 \%$ of cases occurred before the 9th day, 90\%) [10]. The case occurred within the first 18 weeks), so blood pressure should be monitored early after starting treatment (not more than one week), $4 \%$ to $7 \%$ of patients receiving pazopanib which have grade 3 hypertension; approximately $1 \%$ of patients who received pazopanib permanently discontinued treatment due to hypertension [10]. In the literature, an initial goal of blood pressure reduction not more than $25 \%$ within several hours of the onset of PRES using continuous intravenous administration of anti-hypertensive agents was recommended [11]. PRES should be considered as the actual reason for neurologic findings in hypertensive patients with metastatic cancers under TKI therapy. As with other conditions, fluctuations of blood pressure should be avoided and the continuous administration of antihypertensive drugs should be considered under hemodynamic monitoring [12]. In our case, we have been closely monitoring her blood pressure during hospitalization for this patient with end stage renal disease under regular hemodialysis.

\section{Conclusion}

According to the Naranjo algorithm, the PRES was probably related to pazopanib usage, we concluded that pazopanib has probably caused the adverse reactions (Naranjo Algorithm Score of 5) in this patient (shown in Table 3). Medical staff must be aware of the possible association between angiogenic inhibitors therapy and the development of PRES. In patients undergoing treatment with 
Table 3. Naranjo algorithm.

\begin{tabular}{|c|c|c|c|c|}
\hline \multicolumn{5}{|l|}{ Naranjo Algorithm: Pazopanib } \\
\hline Question & Yes & No & $\begin{array}{l}\text { Do Not } \\
\text { Know }\end{array}$ & Score \\
\hline 1) Are there previous conclusive reports on this reaction? & +1 & 0 & 0 & \\
\hline $\begin{array}{l}\text { 2) Did the adverse event appear after the suspected } \\
\text { drug was administered? }\end{array}$ & +2 & -1 & 0 & \\
\hline $\begin{array}{l}\text { 3) Did the adverse reaction improve when the drug was } \\
\text { discontinued or a specific antagonist was administered? }\end{array}$ & +1 & 0 & 0 & \\
\hline $\begin{array}{l}\text { 4) Did the adverse event reappear when the drug was } \\
\text { re-administered? }\end{array}$ & +2 & -1 & 0 & \\
\hline $\begin{array}{l}\text { 5) Are there alternative causes (other than the drug) } \\
\text { that could on their own have caused the reaction? }\end{array}$ & -1 & +2 & 0 & \\
\hline 6) Did the reaction reappear when a placebo was given? & -1 & +1 & 0 & \\
\hline $\begin{array}{l}\text { 7) Was the drug detected in blood (or other fluids) in } \\
\text { concentrations known to be toxic? }\end{array}$ & +1 & 0 & 0 & \\
\hline $\begin{array}{l}\text { 8) Was the reaction more severe when the dose was } \\
\text { increased or less severe when the dose was decreased? }\end{array}$ & +1 & 0 & 0 & \\
\hline $\begin{array}{l}\text { 9) Did the patient have a similar reaction to the same } \\
\text { or similar drugs in any previous exposure? }\end{array}$ & +1 & 0 & 0 & \\
\hline $\begin{array}{l}\text { 10) Was the adverse event confirmed by any } \\
\text { objective evidence? }\end{array}$ & +1 & 0 & 0 & \\
\hline & & & TOTAL & 5 \\
\hline
\end{tabular}

pazopanib, regular monitoring of their blood pressure and follow-up with brain MRI should be encouraged.

\section{Acknowledgements}

None.

\section{Conflicts of Interest}

None to declare. Each author certifies that he or she has no financial organization (e.g. consultancies, stock ownership, equity interest, patent/licensing arrangements, etc.) that might pose a conflict of interest in connection with the submitted article. There are no other conflicts of interest. The case described in the article was performed with funding from Dalin Tzu Chi Hospital, Buddhist Tzu Chi Medical Foundation, Chia-Yi, Taiwan.

\section{References}

[1] Deguchi, S., Mitsuya, K., Nakasu, Y., et al. (2017) Posterior Reversible Encephalopathy Syndrome (PRES) Induced by Pazopanib, a Multi-Targeting Tyrosine Kinase Inhibitor, in a Patient with Soft-Tissue Sarcoma: Case Report and Review of the Li- 
terature. Investigational New Drugs, 36, 346-349.

https://doi.org/10.1007/s10637-017-0521-5

[2] Chelis, L., Souftas, V., Amarantidis, K., et al. (2012) Reversible Posterior Leukoencephalopathy Syndrome Induced by Pazopanib. BMC Cancer, 12, 489-493.

https://doi.org/10.1186/1471-2407-12-489

[3] Asaithambi, G., Peters, B.R., Hurliman, E., et al. (2013) Posterior Reversible Encephalopathy Syndrome Induced by pazopanib for Renal Cell Carcinoma. Journal of Clinical Pharmacy and Therapeutics, 38, 175-176. https://doi.org/10.1111/jcpt.12031

[4] Heudel, P., Cassier, P., Derbel, O., et.al. (2012) Pazopanib for the Treatment of SoftTissue Sarcoma. Clinical Pharmacological, 4, 65-70. https://doi.org/10.2147/CPAA.S33195

[5] Myint, Z.W., Sen, J.M., Watts, N.L., et.al. (2014) Reversible Posterior Leukoencephalopathy Syndrome During Regorafenib Treatment: A Case Report and Literature Review of Reversible Posterior Leukoencephalopathy Syndrome Associated with Multikinase Inhibitors. Clinical Colorectal Cancer, 13, 127-130. https://doi.org/10.1016/j.clcc.2013.12.003

[6] Chae, Y.K., Chiec, L., Adney, S.K., et al. (2018) Posterior Reversible Encephalopathy Syndrome and Takotsubo Cardiomyopathy Associated with Lenvatinib Therapy for Thyroid Cancer: A Case Report and Review. Oncotarget, 9, 28281-28289. https://doi.org/10.18632/oncotarget.25606

[7] Product Information (2013) VOTRIENT(R) Oral Tablets, Pazopanib Oral Tablets. GlaxoSmithKline (per FDA), Research Triangle Park, NC.

[8] Nakano, K. and Takahashi, S. (2018) Current Molecular Targeted Therapies for Bone and Soft Tissue Sarcomas. International Journal of Molecular Sciences, 19, 739-60. https://doi.org/10.3390/ijms19030739

[9] Fischer, M. and Schmutzhard, E. (2017) Posterior Reversible Encephalopathy Syndrome. Journal Neurology, 264, 1608-1616. https://doi.org/10.1007/s00415-016-8377-8

[10] van der Graaf, W.T.A., Blay, J-.Y., Chawla, S.P., et al. (2012) Pazopanib for Metastatic Soft-Tissue Sarcoma (PALETTE): A Randomised, Double-Blind, Placebo-Controlled Phase 3 Trial. The Lancet, 379, 1879-1886. https://doi.org/10.1016/S0140-6736(12)60651-5

[11] Mancia, G., Fagard, R., Narkiewicz, K., et al. (2013) 2013 ESH/ESC Guidelines for the Management of Arterial Hypertension: The Task Force for the Management of Arterial Hypertension of the European Society of Hypertension (ESH) and of the European Society of Cardiology (ESC). Europe Heart Journal, 34, 2159-2219. https://doi.org/10.1093/eurheartj/eht151

[12] Brickman, A.M., Reitz, C., Luchsinger, J.A., Manly, J.J., Schupf, N., Muraskin, J., DeCarli, C., Brown, T.R. and Mayeux, R. (2010) Long-Term Blood Pressure Fluctuation and Cerebrovascular Disease in an Elderly Cohort. Archives of Neurology, 67, 564-569. https://doi.org/10.1001/archneurol.2010.70 